\title{
Evolution of Upwelling-associated Biological Features in the Middle Atlantic Bight as Captured by SAR, SST, and Ocean Color Sensors
}

\author{
P. Clemente-Colón \\ NOAA/NESDIS/ORA \\ 5200 Auth Road, Room 102 \\ Camp Springs, MD 20746-4304
}

\begin{abstract}
Seasonal upwelling in the Middle Atlantic Bight (MAB) occurs during the summer months as a result of episodic wind forcing generally from the south. A wind-generated Ekman divergent surface flow is compensated by an onshore deeper flow that brings nutrient-rich colder waters to the surface. Colder upwelled waters are readily detectable using spaceborne sea surface temperature (SST) observations while increased productivity associated with the enhanced nutrient availability can be imaged by ocean color observations. Low backscatter patterns imaged by synthetic aperture radar (SAR) match closely upwelling patterns observed in the SST data. An abundance of slick filaments also indicated by SAR is consistent with enhanced biological activity associated with the upwelling regime
\end{abstract}

NOAA AVHRR SST, SeaWiFS ocean color (i.e., Chl-a), and RADARSAT-1 SAR imagery of upwelling conditions in the MAB during 1998 were reviewed. The data indicate the development of upwelling centers along the MAB coast. The offshore extension of upwelling-associated filaments as well as offshore blooms is observed in the data. The ability and limitations of these diverse datasets to complement each other in the detection, interpretation, and monitoring of upwellingassociated biological features are explored.

\section{INTRODUCTION}

Seasonal upwelling activity in the Middle Atlantic Bight (MAB) occurs during the summer months as a result of episodic wind forcing from the south. Generally southerly alongshore winds produce an Ekman offshore surface flow. The divergent flow at the surface is compensated by an onshore flow below that brings colder and nutrient-rich waters to the surface along the coast. Upwelled waters can impose significant changes in the atmospheric marine boundary layer stability and in the surface water density relative to the surrounding shelf waters.

Coastal upwelling in the MAB is routinely monitored using NOAA-satellite AVHRR sea surface temperature (SST) data $^{1}$. Synthetic aperture radar (SAR) imaging is now proving to be an effective tool for detecting upwelling-associated features too. Given the right wind speed conditions, temperature changes across water masses as well as the presence and advection of biogenic substances at the sea surface produce distinct signatures in the SAR imagery. In upwelling regions, lower wind stress resulting from increased atmospheric stability over colder waters, the increased damping of Bragg waves over denser waters, and the highly effective damping of Bragg waves by organic surface slicks resulting from enhanced biological activity contribute to create areas of lower backscatter in SAR imagery. In fact, the imaging of natural slick patterns afforded by the high spatial resolution of the SAR data can serve in turn as an indicator of biological activity regions. Historically, ocean color observations of Chl-a such as those obtained from the SeaWiFS spaceborne sensor have been commonly used as indicators of such regions. The ability of SAR sensors to provide day and night through the clouds views of both physical and biological conditions should make it an ideal sensor to complement present thermal and visible monitoring of coastal upwelling dynamics ${ }^{2}$.

\section{SST UPWELLING SIGNATURES}

AVHRR SST images of the MAB available for the summer of 1998 indicate the typical development of localized upwelling centers along the coast. SST observations from the Cape Cod to the North Carolina coast on July 27, 1998 are shown in Fig. 1 as an example. The coldest waters in the image are those associated with the upwelling activity off Cape Cod. Upwelling is also evident off the Hudson Estuary, south of Long Island and off the Delaware Bay mouth region. A much weaker indication of upwelling along the New Jersey coast and off the Chesapeake Bay mouth is also observed at this time. The development of thermal filaments extending from coastal upwelling centers, such as those extending south of Long Island in Fig. 1, can be followed throughout the available SST observations. The offshore warm water of the Gulf Stream is also a major feature consistently observed in the available data.

\section{OCEAN COLOR (BIOLOGICAL ACTIVITY) SIGNATURES}

A limited number of SeaWiFS Chl-a images of the MAB available for the summer of 1998 provided some indication of a link between enhanced biological activity and upwelling conditions as indicated by the thermal imagery. The distribution of SeaWiFS Chl-a concentrations (in $\mathrm{mg} \mathrm{m}^{-3}$ ) along the MAB coast observed just over an hour before the SST data in Fig. 1 is shown in Fig. 2. Again, salient features include several patterns of high Chl-a concentration off Cape Cod, Long Island, Delaware Bay, and Chesapeake Bay. 


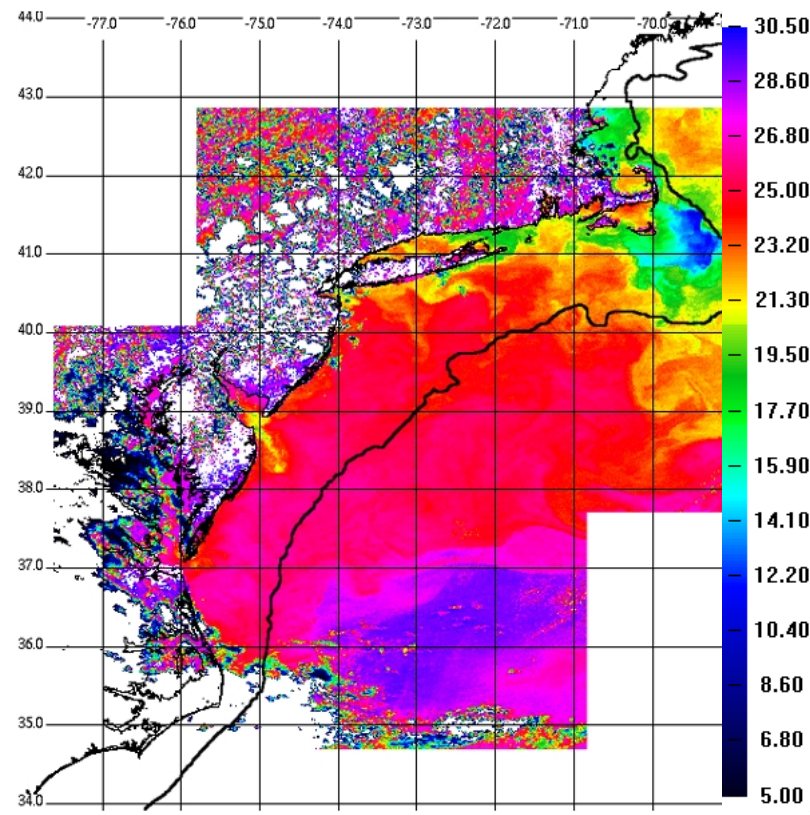

Fig. 1. AVHRR SST (in ${ }^{\circ} \mathrm{C}$ ) observation of MAB coastal upwelling conditions on July 27, 1998 18:54 UTC. The $100 \mathrm{~m}$ isobath is used to indicate the extend of the shelf region.

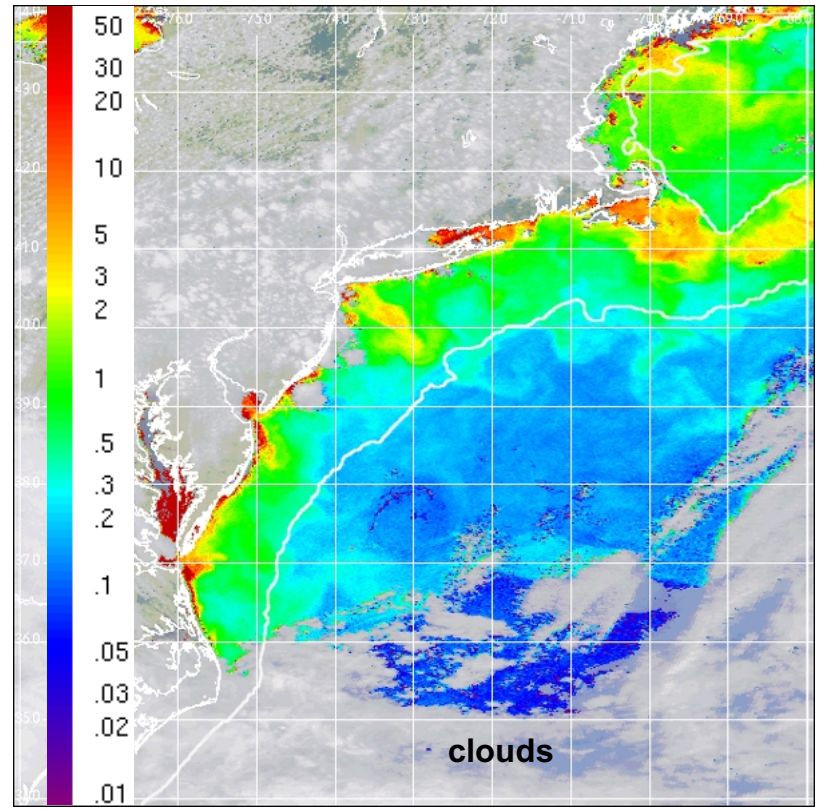

Fig. 2. SeaWiFS Chl-a concentrations (in $\mathrm{mg} \mathrm{m}^{-3}$ ) along the MAB coast on July 27, 1998 17:40 UTC.

Of particular interest is the relatively good spatial correlation between the location of the Chl-a filament extending from the Long Island coast to the outer shelf region and the location of one of the SST filaments observed in Fig. 1. The offshore waters are characterized by much lower Chl-a concentrations particularly over the Gulf Stream.

\section{SST AND SAR UPWELLING FEATURES}

Upwelling conditions along the New Jersey coast intensified dramatically by July 30,1998 , and were captured by both AVHRR SST and RADARSAT-1 SAR as shown in Figs. 3a and $3 \mathrm{~b}$. A direct correspondence between the low SST patterns and low radar backscatter features off the upper coast of New Jersey and the southern cost of Long Island is observed. The upwelling filament that is observed in both SST and ocean color extending southward from Long Island has also been partially captured by SAR. Additional SAR low backscatter features have being imaged in the mid and outer shelf region off New Jersey. Corresponding offshore patterns are not shown by the SST data, however.

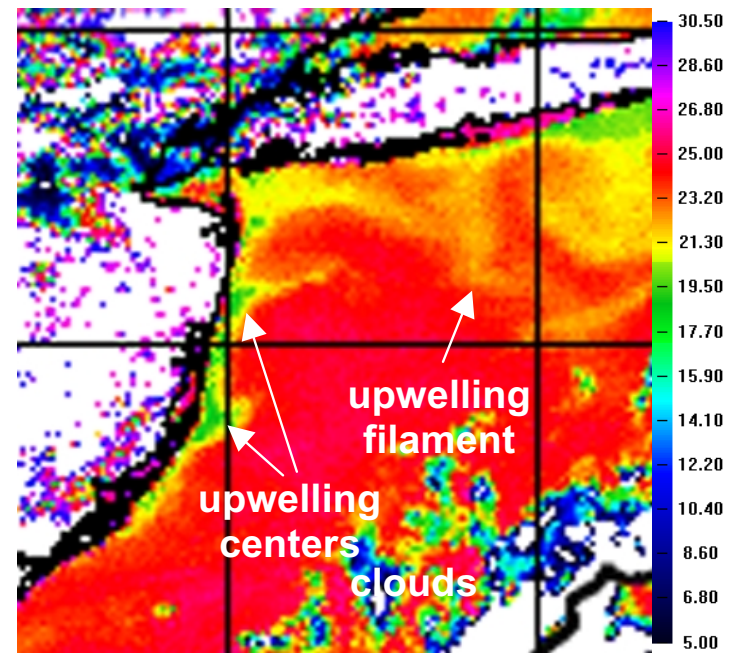

Fig. 3a. Observation of upwelling features off upper New Jersey, the Hudson Estuary, and Long Island as imaged by AVHRR SST (in ${ }^{\circ} \mathrm{C}$ ) on July 30 , 1998 18:32 UTC.

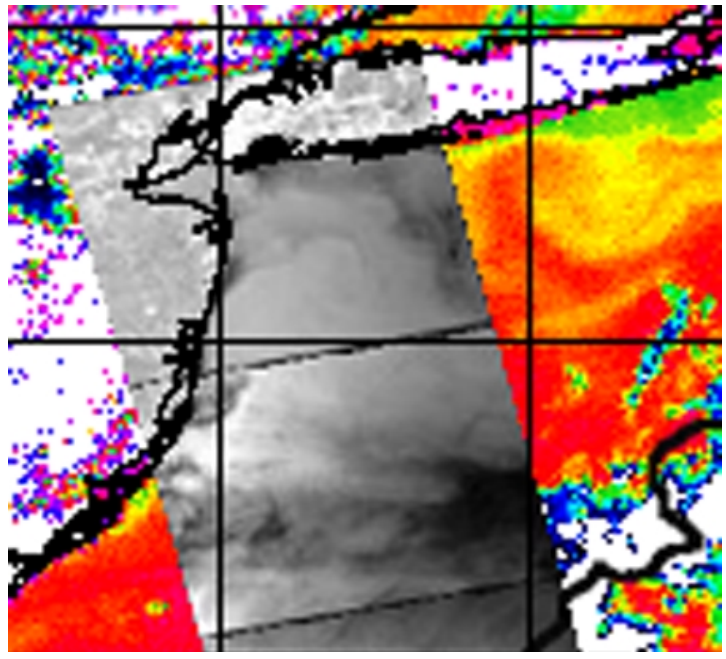

Fig. 3b Observation of upwelling features off upper New Jersey, the Hudson Estuary, and Long Island as imaged by RADARSAT-1Standard Mode SAR frames on July 30, 1998 22:40 UTC. SAR frames are superimposed on the near-coincident AVHRR SST image shown in Fig. 3a. 


\section{OCEAN COLOR AND SAR UPWELLING FEATURES}

SeaWiFS Chl-a data acquired on August 2, 1998, three days after the previous observations, are shown in Fig. 4. A relatively intense Long Island bloom filament is shown extending southward across the shelf. A secondary bloom feature has developed by now in the inner shelf. The location

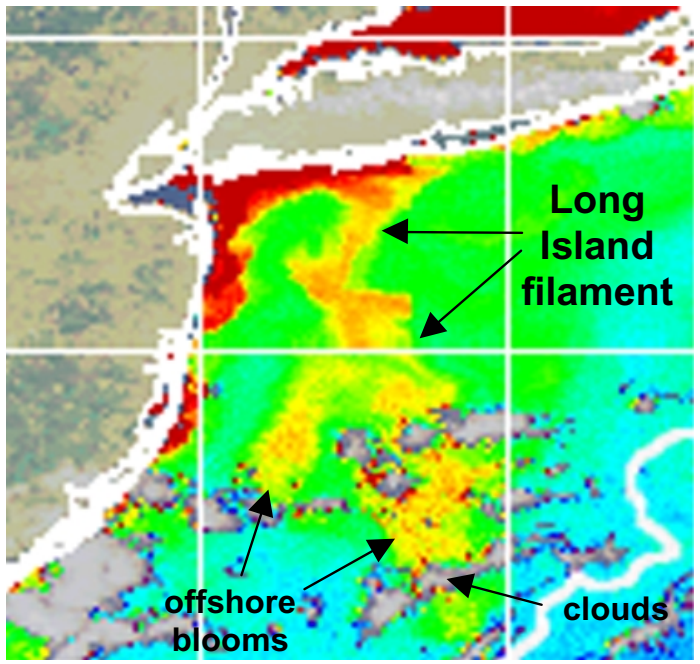

Fig. 4. SeaWiFS Chl-a (in $\mathrm{mg} \mathrm{m}^{-3}$ ) observation of offshore blooms off upper New Jersey and Long Island on August 2, 1998 17:13 UTC.

of the upper part of the filament has clearly moved in a northnorthwest direction from the location observed three days earlier in the SAR data. A similar northward drift is apparent between the center of the offshore bloom regions and the center of the offshore low backscatter features observed in the mid and outer shelf. The close correspondence between these features supports the interpretation the SAR signatures as being the manifestation of offshore biological activity. Although their generation is associated with the upwelling dynamics, these features are no longer detectable using SST observations. A closer look at the offshore bloom region in the SAR image reveals additional details as shown in Figure 5. The offshore blooms and the coastal upwelling centers, as well as the Long Island filament (not shown), are characterized by an abundance of surface slicks. Again, this is consistent with enhanced biological activity. The effect of wind drift can be observed in the alignment of slicks associated with Long Island filament offshore bloom with the general wind direction (i.e., toward the coast). Although wind variability complicates the interpretation of the image, the relatively lower backscatter region aligned with the wind direction and falling between the two offshore bloom features is in fact interpreted as the effect of relatively low wind speeds. Additional ocean color data acquired on August 9, 1998 revealed that the biological activity associated with the Long Island and upper New Jersey upwelling centers further extended offshore across the full shelf.

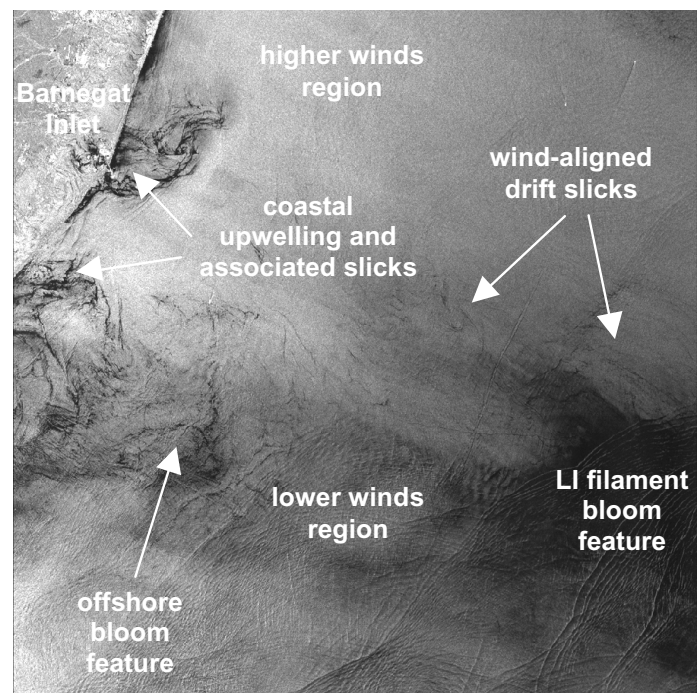

Fig. 5. Close-up of a SAR frame in Fig. 3a (second from the top) showing details of the upwelling and offshore bloom features found off the New Jersey Barnegat Inlet region on July 30, 1998 22:40 UTC.

\section{CONCLUDING REMARKS}

It appears that monitoring of coastal upwelling dynamics could be greatly enhanced by combining observations from thermal, visible, and radar imaging sensors. However, it is important to keep in mind a number of caveats when fusing such datasets. First, observations of Chl-a features indicating various degrees of biological activity in coastal regions are possible throughout the year. Thus, Chl-a observations made at any particular time may not necessarily reflect a response to enhanced upwelling activity in a region. Second, SST and Chl-a upwelling observations do not always correlate, i.e., while their dynamics may initially correlate to some degree, Chl-a and heat fluxes will ultimately not. A case in point is shown by the Cape Cod upwelling patterns in Figs. 1 and 2 where only part of the features coincides precisely. Third, although the abundance of natural slicks appears to be characteristic of regions of enhanced biological activity, observations of increased Chl-a may not always correlate with their presence, which may depend on the degree of development of the biological activity. Fourth, since the presence of surfactants in seawater is indeed ubiquitous, very low wind speed conditions may allow the appearance of slicks to occur even if no significant additional biological activity is present.

\section{REFERENCES}

[1] S.M. Glenn, M.F. Crowley, D.B. Haidvogel, and Y.T. Song, "Underwater observatory captures coastal upwelling events off New Jersey," EOS Trans. of $A G U$, vol. 77 , no. 25, 1996, pp. 233-236.

[2] Clemente-Colón, P. and X.-H. Yan, "Observations of East Coast upwelling conditions in synthetic aperture radar imagery," IEEE Trans. Geoscience and Rem. Sens., vol. 37, no. 5, 1999, pp. 2,239-2,248. 